\title{
Evaluation of Hematological Changes in HIV Infected Pregnant Women After Receiving HAART at Debremarkos Hospital Debremarkos, Ethiopia
}

\author{
Kassahun Dires \\ Department of Pharmacology, College of Medicine, Debreberhan University, Debreberhan, Ethiopia \\ Email address: \\ kassh2009@gmail.com \\ To cite this article: \\ Kassahun Dires. Evaluation of Hematological Changes in HIV Infected Pregnant Women After Receiving HAART at Debremarkos Hospital \\ Debremarkos, Ethiopia. Clinical Medicine Research. Vol. 7, No. 3, 2018, pp. 80-83. doi: 10.11648/j.cmr.20180703.15
}

Received: June 25, 2018; Accepted: July 7, 2018; Published: August 15, 2018

\begin{abstract}
Hematological complications are documented as the second most common cause of morbidity and mortality in HIV/AIDS patients. Drugs for HIV/AIDS showed side effects on different hematological parameters. This study was aimed at assessing the changes in hematological profile of HIV infected pregnant women after initiation of highly active antiretroviral treatment. Retrospective cohort study was conducted to assess the hematological changes in HIV infected pregnant women after initiation of highly active antiretroviral (HAART) at ART clinic of Debremarkos hospital in Ethiopia from May to August 2017. Data available between May 2008 and August 2017 was collected from 380 patient cards of pregnant women. The data was entered into Excel spread sheet and was transported into STATA software for analysis. All data were presented as mean \pm Standard error of the mean. Comparisons were made using the Paired T-test. A p-value of $<0.05$ was considered as a statistically significant difference. The result from the present study shows that the HAART initiation in pregnant women with HIV increases the CD4 cell count, the mean corpuscular hemoglobin concentration, white blood cell count, lymphocyte count and total mid cell count at ninety-five percent confidence interval. From the total of 380 patient cards with complete CD4 count, 200 patient cards were recorded with TDF/3TC/EFV ART regimen. The remaining 180 patient cards were documented with AZT/3TC/NVP regimen. Comparing the effect of the two Regimens on CD4 count, TDF/3TC/EFV increases the CD4 count significantly in pregnant women with HIV $(\mathrm{p}<0.0001)$. The other regimen (AZT/3TC/NVP) also increases the CD4 count from initial value but this increase in CD4 count after AZT/3TC/NVP initiation in pregnant women with HIV is not statistically significant $(\mathrm{P}>0.05)$. HAART initiation in pregnant women with HIV increases lymphocyte count, total mid cell count, red blood cell count, white blood cell count, total hemoglobin, hematocrit, mean cell volume and total platelet. On the contrary, the initial value of granulocyte count, mean cell hemoglobin, mean corpuscular hemoglobin concentration, red cell distribution width and mean platelet volume decreases after antiretroviral treatment in pregnant women with HIV.
\end{abstract}

Keywords: Hematological Parameters, HAART, HIV Positive Pregnant Women

\section{Introduction}

In 2014, 1.2 million people died from HIV-related causes globally. There were approximately 36.9 million people living with HIV at the end of 2014 with 2.0 million people becoming newly infected with HIV in 2014 globally, SubSaharan Africa, with 25.8 million people living with HIV in 2014. Also sub-Saharan Africa accounts for almost $70 \%$ of the global total of new HIV infections [1].

In Ethiopia, the 2014 estimated number of people living with HIV was 769,600 with15,700 new HIV infections and
35,600 AIDS-related deaths [2].

HIV is characterized by progressive damage to the body's immune system which results in the development of a number of opportunistic infections and other complications [3]. The most important biomarkers of disease stage and progression in patients with an HIV infection are the CD4 count and HIV RNA concentration [4]. However, there are other factors that can influence or predict the prognosis. Hematological abnormalities, such as anemia, neutropenia, and thrombocytopenia, are commonly observed in patients infected with HIV [5]. For this reason the total lymphocyte 
count, white blood cell count, and hematocrit or hemoglobin concentration have been proposed as alternative markers of the disease, especially for developing countries where financial resources are limited [6].

The introduction of highly active antiretroviral therapy (HAART) has led to significant reduction in acquired immune deficiency syndrome (AIDS)-related morbidity and mortality. Adverse drug reactions (ADRs) to antiretroviral treatment (ART) are, however, major obstacles in its success. [7]. The Centre for Disease Control (CDC) advocates that before the use of any anti- retroviral therapy, the safety and efficacy of the drug should be tested [8].

There are limited studies conducted on hematological changes in pregnant women after starting HAART regimen in developing countries especially in Ethiopia. This study, therefore, provide information about the change of hematological profile in pregnant women after HAART regimens which may contribute in improving the management of patients after initiation of Anti-retroviral treatment.

\section{Materials and Methods}

\subsection{Study Design and Settings}

Retrospective cohort study was conducted to assess hematological profile of HIV infected pregnant women after initiation of HAART at ART clinic of Debremarkos hospital in Ethiopia from May to August 2017. The type of ART regimen, hematological data (White blood cells, CD4+ T cells, hemoglobin, and Platelet count) and values for other hematological indices were carefully collected from 380 patient follow up cards that were available between May 2008 and August 2017.

\subsection{Data Processing and Analysis}

The data was entered into Excel spread sheet and it was transported into STATA software for analysis. All data were presented as mean \pm Standard error of the mean. Comparisons were made using the Paired T-test. A p-value of $<0.05$ was considered to be statistically significant.

\section{Result}

HAART initiation in pregnant women with HIV increases lymphocyte count, total mid cell count, red blood cell count, white blood cell count, total hemoglobin, hematocrit, mean cell volume and total platelet. On the contrary, the initial value of granulocyte count, mean cell hemoglobin, mean corpuscular hemoglobin concentration, red cell distribution width and mean platelet volume decreases after antiretroviral treatment in pregnant women with HIV.

Among a total of 380 pregnant women, two hundred patients were treated with TDF/3TC/EFV ART regimen and the remaining one hundred eighty received AZT/3TC/NVP (table 1,2).

Table 1. Shows the number of patient cards taken for analysis for each hematological parameter.

\begin{tabular}{ll}
\hline Hematological parameter & number \\
\hline CD4 count & 380 \\
WBC count & 380 \\
Lymphocyte count & 380 \\
Total mid cell count & 380 \\
Granulocyte count & 380 \\
RBC count & 380 \\
Total haemoglobin & 380 \\
Hematocrit & 380 \\
Mean cell volume & 380 \\
Mean cell hemoglobin & 380 \\
Mean cell hemoglobin concentration & 380 \\
Red cell distribution width coefficient of variation & 380 \\
Total platelet count & 380 \\
Mean platelet volume & 380 \\
PCT in percent & 380 \\
\hline
\end{tabular}

Table 2. Shows the number of study participants per treatment regimen.

\begin{tabular}{lll}
\hline \multirow{2}{*}{ ART regimen } & \multicolumn{2}{l}{ Number of patient cards per regimen } \\
\cline { 2 - 3 } & number & $\%$ \\
\hline TDF/3TC/EFV & 200 & 52.64 \\
AZT/3TC/NVP & 180 & 47.36 \\
total & 380 & 100 \\
\hline
\end{tabular}

Comparing the effect of the two Regimens on CD4 count, TDF/3TC/EFV increases significantly the CD4 count in pregnant women with HIV $(\mathrm{p}<0.0001)$. The other regimen (AZT/3TC/NVP) also increases the CD4 count from initial value as it is indicated by positive paired mean difference but this increase in CD4 count after AZT/3TC/NVP initiation in pregnant women with HIV is not statistically significant at 95 percent confidence interval ( $\mathrm{p}>0.05$, table 3$)$.

Table 3. CD4 T-cell changes in pregnant women with HIV per treatment regimen.

\begin{tabular}{|c|c|c|c|c|}
\hline ART regimen & CD4 before & CD4 after & Paired mean difference & P-value \\
\hline TDF/3TC/NVP & $400 \pm 28$ & $600 \pm 47$ & $200 \pm 19$ & $\mathrm{P}<0.0001$ \\
\hline $\mathrm{AZT} / 3 \mathrm{TC} / \mathrm{NVP}$ & $370 \pm 20$ & $378 \pm 25$ & $8 \pm 5$ & $\mathrm{P}>0.05$ \\
\hline
\end{tabular}

Describing the effect on other hematological parameters, HAART initiation in pregnant women with HIV increases the value of lymphocyte count, total mid cell count, red blood cell count white blood cell count, total hemoglobin, hematocrit, mean cell volume and total platelet. On the contrary, the initial value of granulocyte count, mean cell hemoglobin, mean corpuscular hemoglobin concentration, red cell distribution width and mean platelet volume decreases after antiretroviral treatment in pregnant women with HIV ( $p>0.05)$ (table 4). 
Table 4. Hematological changes in pregnant women with HIV after HAART initiation.

\begin{tabular}{llllll}
\hline Hematological parameter & Before HAART (baseline) & After HAART & N & Paired mean difference & P-value \\
\hline CD4 count & $450 \pm 30$ & $575 \pm 35$ & 380 & $125 \pm 5$ & P $<0.0001$ \\
WBC count & $4 \pm 0.5$ & $5.47 \pm 0.3$ & 380 & $1.47 \pm 0.2$ & $\mathrm{P}<0.05$ \\
Lymphocyte count & $1.78 \pm 0.12$ & $1.98 \pm 0.13$ & 380 & $0.2 \pm 0.01$ & $\mathrm{P}<0.05$ \\
Total mid cell count & $0.41 \pm 0.02$ & $0.50 \pm 0.04$ & 380 & $0.09 \pm 0.04$ & $\mathrm{P}<0.05$ \\
Granulocyte count & $2.45 \pm 0.29$ & $2.27 \pm 0.26$ & 380 & $-0.18 \pm 0.28$ & $\mathrm{P}>0.05$ \\
RBC count & $4.04 \pm 0.14$ & $5.46 \pm 0.17$ & 380 & $1.42 \pm 0.15$ & $\mathrm{P}<0.05$ \\
Total hemoglobin & $11.65 \pm 0.52$ & $14.68 \pm 0.42$ & 380 & $3.03 \pm 0.49$ & $\mathrm{P}<0.05$ \\
Hematocrit & $40.44 \pm 0.94$ & $45.35 \pm 1.09$ & 380 & $4.91 \pm 1.22$ & $\mathrm{P}<0.05$ \\
MCV & $90.47 \pm 2.18$ & $96.05 \pm 1.99$ & 380 & $5.58 \pm 1.39$ & $\mathrm{P}<0.05$ \\
MCH & $34.20 \pm 0.91$ & $33.41 \pm 0.79$ & 380 & $-0.79 \pm 0.27$ & $\mathrm{P}>0.05$ \\
MCHC & $35.68 \pm 0.35$ & $34.64 \pm 0.31$ & 380 & $-1.04 \pm 0.39$ & $\mathrm{P}>0.05$ \\
RDWCV & $13.68 \pm 0.26$ & $13.17 \pm 0.25$ & 380 & $-0.51 \pm 0.31$ & $\mathrm{P}>0.05$ \\
Total platelet & $2.00 \pm 15.68$ & $3.54 \pm 19.34$ & 380 & $1.54 \pm 24.07$ & $\mathrm{P}<0.05$ \\
Mean platelet volume & $10.03 \pm 0.50$ & $9.95 \pm 0.41$ & 380 & $-0.08 \pm 0.61$ & $\mathrm{P}>0.05$ \\
\hline
\end{tabular}

Note: all values are expressed as Mean \pm standard error of the mean

$\mathrm{P}<0.0001$ - extremely significant.

$\mathrm{P}<0.05$ - significant.

$\mathrm{P}>0.05$-not significant.

\section{Discussion}

In the present study, CD4 T-cell count was increased after initiation of HAART. For those pregnant women who received TDF/3TC/NVP, the numbers of increased CD4 Tcells were $200 \pm 19$ cells and for those who received AZT/3TC/NVP were $8 \pm 5$ cells. This finding is comparable with other reports done somewhere else. A study conducted in India on AIDS patients showed that Mean baseline CD4+ $\mathrm{T}$ cell count was $112+60 \mathrm{cell} / \mu \mathrm{l}$. After treatment, a CD4 cell count increased by $>50$ cells $/ \mu 1$ in $84.6 \%$ cases [9].

In this finding, RBC count, hematocrit and hemoglobin levels increased from the baseline data $(\mathrm{P}<0.05)$. An observational cohort study done in Tanzania in 2013 described that pregnant woman after receiving zidovudine containing regimen showed that RBC count decreased within the first four weeks HAART intake and then increased [10]. That final increment in RBC count after long term HAART intake in pregnant women is consistent with the current study. Another study showed that Red Blood Cell count (RBC) and Hematocrit (HCT) were significantly reduced compared to control subjects [11] to mean that this report is not consistent with the current study.

Another follow-up study carried out on some hematological and hem rheological changes in HIV-infected pregnant women on highly active antiretroviral therapy in University of Benin Teaching Hospital, Nigeria, from April 2013 to February, 2014 showed that in the first trimester there were no significant changes in $\mathrm{Hb}$ [12]. Another study also was done in Burkina Faso, Kenya and South Africa, 2013 by Cherish et al to assess the effect of triple zidovudine containing regimens, ART eligible pregnant women were followed from 28 weeks of pregnancy $(\mathrm{n}=1070)$. At enrolment (corresponded to a median of 32 weeks gestation), the median hemoglobin was $10.3 \mathrm{~g} / \mathrm{dl}$. Severe anemia occurred subsequently in 194 (18.1\%) of women. After 1-2 months of ARV's, severe anemia was significantly reduced in all groups, though remained highest in the low CD4 cohort and this finding is not in agreement with the current finding.
The current study shows that HAART initiation in pregnant women has significant effect on total platelet and white blood cell count as p-value for both hematological parameters is less than 0.5 when it is compared with the initial value. This is finding is not supported with a follow-up study carried out on some hematological and hem rheological changes in HIV-infected pregnant women on highly active antiretroviral therapy in University of Benin Teaching Hospital, Nigeria, from April 2013 to February, 2014 showed that in the first trimester there were no significant changes in WBC and WBV $(\mathrm{P}>0.05)$ between test and control subjects [12]. A Study conducted in Markurdi, Benue state of Nigeria indicated that ART brings statistically significant increment in WBC from $4070 \pm 250$ cells/ $\mu 1$ at baseline to $4760 \pm 170$ cells/ $\mu 1$ after antiretroviral drugs treatment [3]. The result of a study done in Italy indicated that HAART induced a significant increase in the PLT count within the third month which was sustained up to the sixth month of therapy [13]. This shows that the present finding concerning the effect on platelet count and white blood cell count in pregnant women after HAART is consistent with reports described above.

\section{Conclusion}

In conclusion, HAART initiation in pregnant women with HIV increases lymphocyte count, total mid cell count, red blood cell count, white blood cell count, total hemoglobin, hematocrit, mean cell volume and total platelet. On the contrary, the initial value of, granulocyte count, mean cell hemoglobin, mean corpuscular hemoglobin concentration, red cell distribution width and mean platelet volume decreases after antiretroviral treatment in pregnant women with HIV.

\section{Abbreviations and Acronyms}

$\begin{array}{ll}\text { AIDS } & \text { Acquired Immune Deficiency Syndrome } \\ \text { ART } & \text { Anti Retroviral Therapy } \\ \text { AZT/ZDV } & \text { Zidovudine }\end{array}$




$\begin{array}{ll}\text { CDC } & \text { Centre for Disease Control and Prevention } \\ \text { HAART } & \text { Highly Active Antiretroviral Therapy } \\ \text { HCT } & \text { Hematocrit } \\ \text { HGB } & \text { Hemoglobin } \\ \text { HIV } & \text { Human Immunodeficiency Virus } \\ \text { MCH } & \text { Mean cell hemoglobin } \\ \text { MCHC } & \text { Mean corpuscular hemoglobin concentration } \\ \text { MPV } & \text { Mean platelet volume } \\ \text { NRTI } & \text { Nucleoside reverse transcriptase inhibitor } \\ \text { NRTI } & \text { Nevirapine } \\ \text { RBC } & \text { red blood cell } \\ \text { RDW } & \text { Red cell distribution width } \\ \text { SPSS } & \text { Statistical Package for Social Science } \\ \text { 3TC } & \text { Lamivudine } \\ \text { WBC } & \text { White blood cells } \\ \text { WHO } & \text { World Health Organization }\end{array}$

\section{Acknowledgements}

I would like to thank mr Nigus Zegeye for initiating me to conduct this research. Debremarkos Hospital patient card manager is also acknowledged for his cooperation during data collection.

\section{Conflict of Interest}

The authors declare that they have no competing interests.

\section{Ethics Approval and Consent to Participate}

Ethical clearance was obtained from the Ethics Review Committee of College of Medicine, Debreberhan University. Official letter was written to the head of the hospital to obtain permission to collect the data. Patient information obtained from patient cards was kept confidential.

\section{References}

[1] WHO, HIV report 2015

[2] Ethiopia, HIV report 2015.
[3] Omoregie R, Omokaro EU, Palmer O, Ogefer HO, Egbeobauwuaye A, Adeghe JE, et al. Prevalence of anemia among HIV-infected patients in Benin City, Nigeria. Tanzania J of Health Res. 2009; 11(1). 1-4.

[4] Anastos K, Kalish LA, Hessol N, Weiser B, Melnick S, Burns D. The relative value of CD4 cell count and quantitative HIV1 RNA in predicting survival in HIV-1-infected women: results of the women's interagency HIV study. AIDS. 1999; 13(17):17-26.

[5] Sabin CA, Griffioen A, Yee TT, Emery VC, Herrero-Martinez E, Phillips AN. Markers of HIV-1 disease progression in individuals with hemophilia coinfected with hepatitis $\mathrm{C}$ virus: a longitudinal study. Lancet. 2002; 360:1546-51.

[6] Harbol AW, Liesveld JL, Simpson-Haidaris PJ, Abboud CN. Mechanisms of cytopenia in human immunodeficiency virus infection. Blood Rev. 1994; 8:241-51.

[7] Akhtar M. Hematological Abnormalities among HIV/AIDS Patients on Zidovudine Containing Anti-retroviral Therapy. Ann. Pak. Inst. Med. Sc. 2008; 4(3): 132-135.

[8] National Institute for Allergy and Infectious Disease (NIAID), Division of AIDS (2009). Table for grading the severity of adult and pediatric adverse events, version 1. 0 (2004), Clarification Augus 2009. Available at: http://rsc.tech-res

[9] Vrisekoop N, Gent R, Boer AB, Otto SA, borleffs J, Steingrover R, et al. Restoration of the CD4 cell compartment after long term Highly Active Antiretroviral Therapy without Phenotypical Signs of Accelerated Immunological AgingJ. Immunol. 2008; 181:1573-1581.

[10] Ziske J, Kunz A, Sewangi J et al. Hematological changes in women and infants exposed to an AZT-containing regimen for prevention of mother to child transmission of HIV in Tanzania. Plos One. 2013; 8(2):1-9.

[11] Daniel N, Aryee T and Evelyn A. Profiling Hematological Changes in HIV Patients Attending Fevers Clinic at the Central Regional Hospital in Cape Coast, Ghana: A CaseControl Study. Arch. Appl. Sci. Res. 2011; 3 (5):326-331.

[12] Osime EO, Aniegbune I. Some hematological and hem rheological changes in HIV- infected pregnant women on highly active antiretroviral therapy. Afr J Med Health Sci. $2015 ; 14(1): 4-7$.

[13] Carbonara S, Fiorentino G, Serio G, Maggi P, Ingravallo G, Monno L, et al 2001. Response of severe HIV-associated thrombocytopenia to highly active antiretroviral therapy including protease inhibitors. J Infect. May. 2001; 42(4):251256. 